\title{
In Situ Detection of Macronutrients and Chloride in Seawater by Submersible Electrochemical Sensors
}

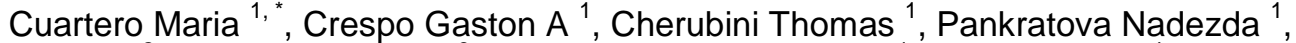 \\ Confalonieri Fabio ${ }^{2}$, Massa Francesco ${ }^{3}$, Tercier-Waeber Mary-Lou ${ }^{1}$, Abdou Melina ${ }^{4}$, Schaefer Joerg ${ }^{4}$, \\ Bakker Eric ${ }^{1,{ }^{*}}$
}

\footnotetext{
${ }^{1}$ Department of Inorganic and Analytical Chemistry, University of Geneva, Quai Ernest-Ansermet 30, $\mathrm{CH}-1211$ Geneva, Switzerland.

2 Idronaut, Via Monte Amiata 10, I-20047 Brugherio (MI), Italy

${ }^{3}$ Department of Earth, Environment and Life Sciences, University of Genoa, C.so Europa 26, 16132

Genoa, Italy

${ }^{4}$ Université de Bordeaux, UMR CNRS 5805 EPOC, Bat 18, Allée Geoffroy Saint-Hilaire, 33615 Pessac, France

* Corresponding authors : Maria Cuartero, email address : mariacb@kth.se ; Eric Bakker, email address : eric.bakker@unige.ch
}

\begin{abstract}
:
A new submersible probe for the in situ detection of nitrate, nitrite and chloride in seawater is presented. Inline coupling of a desalination unit, an acidification unit and a sensing flow cell containing all-solidstate membrane electrodes allows for the potentiometric detection of nitrate and nitrite after removal of the key interfering ions in seawater, chloride and hydroxide. Thus, the electrodes exhibited attractive analytical performances for the potentiometric detection of nitrate and nitrite in desalinated and acidified seawater: fast response time (t95<12 s), excellent stability (long-term drifts of $<0.5 \mathrm{mV} \mathrm{h}-1$ ), good reproducibility (calibration parameter deviation of $<3 \%$ ) and satisfactory accuracy (uncertainties $<8$ $\%$ Diff compared to reference technique). The desalination cell, which can be repetitively used for about 30 times, may additionally be used as an exhaustive, and therefore calibration-free, electrochemical sensor for chloride and indirect salinity detection. The detection of these two parameters together with nitrate and nitrite may be useful for the correlation of relative changes in macronutrients levels with salinity cycles, which is of special interest in recessed coastal water bodies. The system is capable of autonomous operation during deployment, with routines for repetitive measurements (every two hours), data storage and management, and computer visualization of the data in real time. In situ temporal profiles observed in the Arcachon Bay (France) showed valuable environmental information concerning tide-dependent cycles of nitrate and chloride levels in the lagoon, which are here observed for the first time using direct in situ measurements. The submersible probe based on membrane electrodes presented herein may facilitate the study of biogeochemical processes occurring in marine ecosystems by the direct monitoring of nitrate and nitrite levels, which are key chemical targets in coastal waters.
\end{abstract}




\section{INTRODUCTION}

Marine environments are vulnerable to a wide range of substances originating from anthropogenic activities that may have adverse effects on water quality. ${ }^{1-3}$ While certain compounds are important for the dynamic functioning of aquatic ecosystems, the disturbance of its natural equilibrium may have serious impact on living organisms and ultimately on human health. This is the case for freshwater discharges of high macronutrients content from extensive activities such as agriculture. ${ }^{4,5}$ Thus, uncompensated levels of inorganic nitrogen along recessed coastal water bodies such as bays, estuaries, gulfs, sounds or bights, may lead to the gradual eutrophication of the ecosystem if the connected ocean/sea is not able to naturally dilute these inputs. ${ }^{6}$ It is important to identify the sources as well as day/night and tide-dependent concentration distributions of certain compounds such as nitrate and nitrite, at the appropriate temporal and spatial scale. This would greatly help in (i) the understanding of ecosystems disturbance, (ii) risk evaluation and (iii) the management and mitigation of environmental impact, especially when anomalous concentrations exceeding expected levels range in coastal zones (i.e. $0.1-40 \mu \mathrm{M}$ for nitrate and $0.01-4 \mu \mathrm{M}$ for nitrite) occur. ${ }^{7,8}$ Current existing monitoring programs mostly work with monthly measurements, which do not account for short-term variations of nitrate/nitrite and other chemical parameters in coastal water bodies.

For the reasons described above, there is an urgent need for analytical tools to monitor nitrate and nitrite in marine ecosystems. Detection achieved in real time and in situ is clearly preferred over centralized approaches, which require discrete sampling, in order to minimize the risk of sample contamination or degradation and drastically increase the frequency of data acquisition. ${ }^{9}$ Few analytical techniques offer the required characteristics for their implementation in situ, and it is therefore important to exploit the application of those techniques that may provide local environmental observations through deployable devices. In this regard, flow injection systems based on the Griess reaction to detect nitrite and additionally incorporating a Cd reduction column to detect nitrate have been extensively adapted for in situ measurements. ${ }^{10-14}$ However, the degree of complexity of these deployable devices is high and sometimes only the determination of total oxidized nitrogen $\left(\mathrm{NO}_{3}{ }^{-}+\mathrm{NO}_{2}{ }^{-}\right)$is accessible. ${ }^{11}$ On the other hand, submersible ultraviolet nitrate analysers that are chemicals free have also been proposed in the literature and are even commercialized. ${ }^{15,16}$ Yet, the precision reported in seawater $(2.4 \mu \mathrm{M})$ related to detector drift does not provide sufficiently accurate data. 
Nitrate/nitrite micro-biosensor developed by Revsbech et al. is another promising tool for in situ measurements as it has been demonstrated in specific cases such as sediment profiling. ${ }^{17,18}$ However, the authors realistically stated that the construction of the electrodes is complicated and that the bacterial cultures used in the sensor should always be fresh. Moreover, incubation conditions change according to the expected temperature and there are also other issues related to the sensor calibration. Macrosensor based on the same concept is currently commercially available to measure concentrations greater than $0.2 \mu \mathrm{M}$ of nitrate and nitrite, operating between $10-38^{\circ} \mathrm{C}$ with signal drift $<20 \%$ per week and no pressure tolerance. ${ }^{19}$ The sensor is not currently applicable for in situ measurements as the manufacturer suggests not to submerse it below $1 \mathrm{~m}$ but to perform sampling and on deck measurements (on site) instead. An alternative to the mentioned in situ probes may be the use of a submersible device based on electrochemical sensors and particularly all-solid-state electrodes based on ion sensing membranes (ISMs), which have demonstrated excellent functionality for in situ environmental analysis in the last decade..$^{8,20}$

Solid state membrane electrodes are fabricated by modifying the surface of a conductive material (i.e. glassy carbon, gold) with a suitable ion-to-electron transduction material (i.e. conducting polymers, nanomaterials) and subsequently coated by the ISM, which typically contains a polymeric matrix, a plasticizer, an ion-exchanger and a selective chemical receptor (ionophore). ${ }^{21,22}$ The response mechanism of ISMs is governed by a local ion distribution equilibrium at the sample-membrane interface. When operating at zero current potentiometry, an activity change of the primary ion in the aqueous solution ideally results in a well-defined change of the membrane potential that is governed by the Nernstian relationship. ${ }^{23}$ Ion-sensing membranes may alternatively also be interrogated by dynamic electrochemistry by applying either a linear sweep or a constant potential or current, giving additional analytical information about the system. ${ }^{24-26}$ Whatever the ISM readout, the required instrumentation is comparatively inexpensive, readily miniaturized and easy-to-use. In addition, inherent characteristic of solidstate electrodes (versatility, simplicity, low cost, reduced size, fast response time, insensitivity to pressure and light $)^{8,20}$ make them particularly suited for in situ aquatic analysis by submersible probes.

Field applications of potentiometric membrane sensors for in situ water monitoring have been described in recent years. Athavale et al. described the implementation of all-solid-state ammonium-selective electrodes in a custom-built Profiling Ion Analyser (PIA) deployed in a 
stratified lake. ${ }^{27,28}$ The observed depth profiles for ammonium concentration showed fine scale features, which would go unnoticed using discrete sampling-based analysis, allowing for the identification of hotspots and step gradients of ammonium levels in the lake. The direct contact of the membrane electrodes with the water column and the profiling by the PIA at a continuous speed make it possible to acquire high resolution depth profiles. More recently, our group has developed a submersible probe based on a potentiometric flow cell containing $\mathrm{pH}$, carbonate and calcium membrane electrodes applicable to seawater analysis. ${ }^{29}$ The flow module in the probe permits the single-point re-calibration of the electrodes and an improved biofouling resistance for long-term experiments. In situ temporal profiles of $\mathrm{pH}$, carbonate and calcium observed through the deployment of the device at different marine locations demonstrated that it is a promising tool for environmental analysis.

We present here a new submersible potentiometric probe for real time detection of nitrate and nitrite in seawater. Nitrate and nitrite-selective miniaturized all-solid-state sensors based on nanomaterials are accommodated in a flow cell developed in house that allows the coupling of inline desalination and acidification pretreatments to reduce the limit of detection of the macronutrients in seawater as much as possible. ${ }^{30,31}$ The desalination cell is here also used as a calibration-free electrochemical sensor for chloride detection, which is in turn correlated to salinity data. The developed fluidics system is incorporated into a deployable device, offering autonomous operation and a single-point re-calibration of the nitrate and nitrite electrodes, therefore compensating for possible potential-time drifts in the electrodes responses. The system was deployed in the Arcachon Bay (France) for $23 \mathrm{~h}$, recording nitrate, nitrite and chloride levels along the tidal changes in the lagoon and validated with traditional sampling techniques. 


\section{EXPERIMENTAL SECTION}

Description of the potentiometric sensors. Miniaturized glassy carbon electrodes were fabricated in house as previously reported (see Supporting Information). ${ }^{29}$ A film of modified carbon nanotubes (f-MWCNTs) was deposited on top of each electrode by drop casting $5 \times 5 \mu \mathrm{L}$ of the f-MWCNTs solution in THF $\left(1 \mathrm{mg} \mathrm{mL}^{-1}\right),{ }^{32}$ allowing each layer to dry for $10 \mathrm{~min}$ before depositing the next layer. Then, the corresponding membrane cocktail (see Supporting Information for composition) was drop cast on the top of the f-MWCNTs film $(4 \times 10 \mu \mathrm{L})$, allowing each layer to dry for $20 \mathrm{~min}$. The coated electrodes were conditioned overnight ( 12 hours) in $10^{-3} \mathrm{M} \mathrm{HCl}, 10^{-4} \mathrm{M} \mathrm{NaNO}_{3}$ or $10^{-4} \mathrm{M} \mathrm{NaNO}_{2}$, correspondingly, before being accommodated in the flow cell.

Description of the desalination and acidification units. The design of the desalination and acidification cells was previously reported. ${ }^{30,31}$ Dimensions of this first prototype of the desalination cell were modified here in order to increase the volume of the desalinated seawater plug (see Figure S1). Thus, the cell contains the following parts between two acrylic pieces $(60 \times$ $120 \times 20 \mathrm{~mm})$ tightly pressed by screws, in this order: $\mathrm{Ag} / \mathrm{AgCl}$ foil $(50 \times 100 \mathrm{~mm})$, a piece of FKL membrane (cation-exchange membrane, $50 \times 100 \times 0.120 \mathrm{~mm}$ ) sandwiched between two serpentine channels made of natural latex rubber $(50 \times 100 \mathrm{~mm}), \mathrm{Ag}$ foil $(50 \times 100 \mathrm{~mm})$. Note that the membrane divides the cell into two parts: (i) a compartment for seawater desalination $(175 \mu \mathrm{L})$ in contact with the working electrode (Ag foil) and (ii) a reservoir for the reference solution $(175 \mu \mathrm{L}, 600 \mathrm{mM} \mathrm{NaCl}$ or seawater) in contact with the counter/reference electrode ( $\mathrm{Ag} / \mathrm{AgCl}$ foil).

Description of the submersible probe. The designed fluidics for chloride and nutrients detection is presented in Figure 1a. Pump 1 is used to flush the "in situ calibration solution" (stored in a bag), which is also used for the regeneration of the desalination unit (see below), while pump 2 is used for the acid (stored in another bag) needed in the acidification module as well as the seawater for both (i) to be measured in the potentiometric flow cell and (ii) to be utilized as reference solution in the desalination module. All this constitutes the external part of the fluidics, which is connected to the internal part by a special cap with nuts for water/air pressure resistance. ${ }^{29}$ The internal fluidics is placed inside a submersible housing made of acetal copolymer (Delrin) ${ }^{33}$ and is based on a two-position valve, the desalination module, the acidification module and the potentiometric flow cell, in this order (Figure 1b). The valve is 
placed before the desalination cell, allowing for the switch between the "in situ calibration solution" (composition: $3 \times 10^{-6} \mathrm{M} \mathrm{NaNO}_{3}, 1 \times 10^{-6} \mathrm{M} \mathrm{NaNO}_{2}$ and $5 \times 10^{-3} \mathrm{M} \mathrm{NaCl}$ ) and the seawater. The outlet of the desalination unit is connected to the inlet of the acidification unit. The outlet of the acidification unit is connected to the inlet of the potentiometric flow cell. There is also one channel containing the reference solution (seawater) needed for the desalination cell and another one to provide the acid solution $(0.1 \mathrm{M} \mathrm{HCl})$ for acidification. Both solutions are safely discharged into the environment together with the outlet of the potentiometric cell.

We have recently reported on a submersible device for the detection of species relevant to the carbon cycle based on two physical parts (two different housings that are connected): one containing the electronics to control the system and the other containing the fluidics needed for the potentiometric sensing. ${ }^{29}$ If this latter is disconnected, the submersible housing developed here to detect nutrients and chloride can instead be coupled to the electronics part. Indeed, the same electronics (hardware for pump and valves control, potentiometric measurements, voltammetric measurements, the adjustment of the experimental protocol, data acquisition, storage and management) is combinable with either probe, (i) sensors for species relevant to the carbon cycle or (ii) chloride and nutrients sensors, for deployment in seawater. 


\section{RESULTS AND DISCUSSION}

The need of reducing chloride and hydroxide levels to achieve adequate potentiometric detection of nutrients in environmental waters has recently been demonstrated. ${ }^{30,31,34,35}$ The sensitivity of nitrate and nitrite selective electrodes drastically improves with diminishing concentrations of these two interferences while levels of other common ions present in environmental waters do not appreciably affect the response of the probes. ${ }^{30,31}$ Figure 2 shows calibration graphs of miniaturized all-solid-state nitrate and nitrite potentiometric sensors incorporated in a flow cell described earlier (see Experimental section). ${ }^{29}$ In the case of nitrate, no response is observed in $600 \mathrm{mM} \mathrm{NaCl}$ background at $\mathrm{pH} 8$ (seawater conditions). For chloride background concentrations that are reduced down to millimolar levels, however, micromolar limits of detections are achieved $\left(2 \times 10^{-6} \mathrm{M}\right)$. Even lower values are obtained $\left(9 \times 10^{-7} \mathrm{M}\right)$ if additionally the $\mathrm{pH}$ is reduced down to 5.5. In this latter case, a close to Nernstian electrode slope is observed $(-55.4 \mathrm{mV})$.

With nitrite, the same decrease in chloride concentration improves the limit of detection from $5 \times 10^{-4} \mathrm{M}$ to $1 \times 10^{-5} \mathrm{M}$ and values lower than micromolar $\left(6 \times 10^{-7} \mathrm{M}\right)$ with a close to Nernstian slope $(-55.7 \mathrm{mV})$ are observed at $\mathrm{pH}$ 5.5. Other analytical performances of the sensors such as response time, drift and between-day reproducibility are adequate for in situ seawater analysis (see Table S1). The observed limits of detection are suitable to analyze nitrate and nitrite in seawater from locations such as coastal zones and areas strongly influenced by freshwater inputs, as well as to detect anomalous levels in aquatic systems with eutrophic features, ${ }^{7}$ but are far from the nanomolar levels required in oligotrophic open ocean. ${ }^{13}$ If inline pretreatments for sample desalination and acidification are coupled prior to the potentiometric flow cell, in situ detection may be accomplished in the mentioned cases.

In this context, we explore here the possibilities of coupling electrochemical desalination and passive acidification modules to the characterized potentiometric flow cell containing nitrate, nitrite and additionally $\mathrm{pH}$ potentiometric sensors in order to enable in situ seawater analysis (the $\mathrm{pH}$ electrode is used to qualitatively control the final $\mathrm{pH}$ achieved after the pre-treatment to confirm its correct operation, see below and Supporting Information for more details). Thus, when a sufficiently positive constant potential is applied between the working and the reference electrode of the desalination cell, chloride is removed from the seawater down to millimolar levels by exhaustive electrochemical plating as silver chloride on the working electrode (silver 
sheet). ${ }^{30}$ Subsequently, the $\mathrm{pH}$ of the desalinated seawater plug is reduced down to $\sim 5$ owing to the cation-exchange process established between the sample and the acid form of the ionexchange Donnan exclusion membrane. ${ }^{31}$ While the general design of the acidification cell was as reported, ${ }^{31}$ the design and materials of the desalination cell were further optimized compared to the prototype published previously, in order to increase the volume of the desalinated plug available for the potentiometric detection (see Experimental Section and Figure S1a). ${ }^{30}$ Thus, the designed channels based on natural rubber (Figure S1b) and the use of bigger silver sheets as electrodes allows for the increase of the volume in the sample reservoir from ca. $80 \mu \mathrm{L}$ to 175 $\mu \mathrm{L}$.

The efficiency of the desalination process in this new cell was first explored in a $600 \mathrm{mM} \mathrm{NaCl}$ sample at different excitation pulses during several time periods. The chloride concentration in the desalinated plug was calculated from conductivity, by coupling the ion chromatography detector (see Supporting Information) to the outlet of the desalination cell. As observed in Figure $\mathrm{S} 2 \mathrm{a}$, the desalination efficiency increased with increasing applied potential up to $700 \mathrm{mV}$ and then remained almost constant at higher values. Optimum efficiency at $800 \mathrm{mV}$ was achieved after $300 \mathrm{~s}$ of electrolysis time (Figure S2b). A decrease of chloride concentration from 600 to $4.8 \pm 0.1 \mathrm{mM}(\sim 99.2 \%$ efficiency) was achieved using these conditions. A subsequent regeneration step at a cathodic potential of $-900 \mathrm{mV}$ for $600 \mathrm{~s}$ (doubling the time used for desalination) $)^{34}$ in $5 \mathrm{mM} \mathrm{NaCl}$ assured the recovery of $\sim 99.5 \%$ of the chloride deposited on the working electrode, as calculated from conductivity measurements of the collected samples after this regeneration step.

The optimized protocol was then used for the desalination of actual seawater samples, obtaining chloride concentrations of $5.11 \pm 0.23 \mathrm{mM}$ (Figure S3 shows an example of the observed current profiles for desalination and regeneration processes). The lifetime of the cell operating in seawater is currently 30 cycles of desalination, likely due to the deterioration of the silver elements of the cell with the repetitive plating/release of chloride on their surfaces, which is an incomplete process ( $<99.5 \%$ of surface recovery). At the same time the membrane also deteriorates, as silver chloride complexes are being precipitated there at such high concentration of $\mathrm{NaCl}$ in seawater. This limitation was already observed in the first reported prototype. ${ }^{30}$ The lifetime of the desalination cell is currently the limiting factor for the lifetime of the detection system (comprising desalination + acidification + potentiometric detection) applied to in situ 
measurements. A replacement of the exhausted unit is currently required to use the submersible device for longer periods.

If the desalination cell is interrogated using cyclic voltammetry rather than at constant potential, it may also function as a coulometric electrochemical chloride sensor. Figures $3 \mathrm{a}$ and $3 \mathrm{~b}$ show the voltammograms obtained at increasing concentrations of $\mathrm{NaCl}$ ( $\mathrm{scan}$ rate $=2 \mathrm{mV} \mathrm{s}^{-1}$ ) using synthetic samples prepared from $\mathrm{NaCl}$ solutions as well as freshwater/seawater mixtures (the chloride concentration was calculated from ion chromatrography). The peak current and the integrated charge under the peak both follow a linear relationship with the chloride concentration in the sample. Moreover, the use of the integrated charge results in a universal equation that can be utilized without re-calibrating the cell during its lifetime and that is temperature independent (i.e., integrated charge of $600 \mathrm{mM}$ solution at $5-31^{\circ} \mathrm{C}$ was $10.14 \pm 0.01 \mathrm{C}$, scan rate $=2 \mathrm{mV} \mathrm{s}^{-1}$ ). Table S2 presents the calibration graphs obtained in the mentioned $\mathrm{NaCl}$ solutions over time using two desalination cells. The low variation found for the slope (1.2\%) and the intercept $(3.1 \%)$ over three weeks of operation, together with the fact that the calibration graphs obtained for different desalination cells are very close, point out the calibration-free ability of the exhaustive cell as chloride sensor.

Cyclic voltammograms obtained for $600 \mathrm{mM} \mathrm{NaCl}$ at different scan rates are shown in Figure S4. As observed, it is necessary to operate at low scan rate $\left(\leq 2 \mathrm{mV} \mathrm{s}^{-1}\right)$ in order to obtain a constant charge of chloride deposited on the working electrode as $\mathrm{AgCl}$ (anodic scan) that is sufficiently close to the theoretical charge associated to the exhaustive deposition of the chloride contained in the entire volume of the cell $(10.13 \mathrm{C})$. Note that the unequivocal use of low scan rates for exhaustive detection of halides based on thin layer samples that are controlled by cyclic voltammetry was already proposed in the literature and hence, the behaviour found here for chloride detection at different scan rates is in principle expected. ${ }^{36}$ While this restricts the sample throughput of the chloride coulometric sensor, its use allows one to precisely quantify the chloride content of the sample in tandem with the analysis of macronutrient levels.

In order to validate chloride detection in environmental waters, the developed desalination unit was tested over the entire salinity gradient of the Gironde Estuary (France). Several samples ranging from minimum to maximum salinity $(S=0-35$, see Table $S 3)$ were collected and analysed using additionally ion chromatography (IC). As observed in Figure 3c, the linear correlation between the chloride concentrations calculated from IC and voltammetry 
measurements as well as the low average uncertainty, $1.7 \%$ Diff, validate the use of the desalination cell as chloride detector in samples ranging from freshwater to seawater. In addition, there is a correlation between salinity and chloride content (Figure 4a) that may be used to calculate salinity from chloride measurements and vice versa.

In this regard, there are two chief methods for determining the salt content (salinity) of water: Total Dissolved Salts (TDS) and Electrical Conductivity measurements (EC). Indeed, EC can be used to give an estimate of TDS as measurement of TDS is tedious and cannot be carried out in the field (EC measurement is much quicker and simpler). While EC covers salinity ranges from ca. 25-42 with acceptable accuracy, its use in low salinity waters is however limited ${ }^{37,38}$ and consequently the desalination unit may provide an alternative for in situ salinity measurements in most types of natural water. Optical sensors ${ }^{[39-41]}$ are currently emerging for this same purpose, but they have not yet been implemented for in situ measurements and field data continue to be extracted from EC measurements using CTD multiparameter probes.

Figure $4 \mathrm{a}$ presents the plot of EC salinity versus measured chloride in the samples from the Gironde Estuary. The linear relationship is maintained for the higher salinity samples (from 15 to 35) while low salinity samples show some deviation (from 0 to $15 \mathrm{PSU}$ ) that is assigned to the less reliable use of EC under low salinity conditions. On the other hand, the accuracy in the integration of the voltammetric peak decreases with decreasing chloride concentration as a consequence of the flattening of the voltammetric wave, which becomes barely readable for chloride concentrations lower than $3 \mathrm{mM}$ (see Figure S5), marking the lowest detectable chloride concentration by this desalination module.

Before the in situ implementation of the developed system composed of desalination cell, acidification cell and potentiometric flow cell for nitrate, nitrite and additionally chloride detection, laboratory validation of seawater samples analysis was performed. Table 1 collects the results obtained for seawater samples from different locations (calibrations of the sensors and experimental protocol for the samples analyses are detailed in Supporting Information). The initial $\mathrm{pH}$ of the sample was measured using a $\mathrm{pH}$ meter while the $\mathrm{pH}$ electrode in the potentiometric flow cell controlled the $\mathrm{pH}$ after the pre-treatment in these laboratory measurements. Nitrate and nitrite levels of the analysed samples were additionally measured using colorimetry and chloride by IC. As observed in the table, a good correlation with the selected reference technique was obtained in all the cases, with uncertainties $<8 \%$ Diff. The 
measured $\mathrm{pH}$ after the desalination-acidification pretreatment was always close to 5, confirming that the system functioned properly. If for any reason the desalination module would fail, the $\mathrm{pH}$ of the treated seawater sample would approach 2 because the higher $\mathrm{Na}^{+}$content in the sample will result in a larger $\mathrm{H}^{+}$exchange with the membrane. ${ }^{28}$ This dysfunction would be immediately identified, therefore preventing the calculation of erroneous nitrate and nitrite levels. The desalinated and acidified plug is associated with a drastic change in the signal (Figure S6): i.e. nitrate and nitrite potentiometric responses are higher as a consequence of the decrease of chloride and hydroxide concentration in the modified plug; on the other hand, the potential readout of the $\mathrm{pH}$ electrode is higher because the $\mathrm{pH}$ obtained after acidification is lower than the one for unmodified seawater as mentioned above.

In situ measurements of nitrate, nitrite and chloride in the Arcachon Bay (France). In situ operation of the sensors was demonstrated during a $23 \mathrm{~h}$ deployment in the Arcachon Bay. For this purpose, the system (desalination unit + acidification unit + potentiometric cell) was implemented in a submersible housing (see Figure 1b), similar to that previously developed for the potentiometric detection of species relevant to the carbon cycle in seawater, ${ }^{26}$ and mounted in a titanium cage for the joint deployment with other probes (i.e. CTD multiparameter probe), see Experimental section and Figure 1a-d for more details. The submersible device was deployed from a boat (the R/V Planula IV) placed in a stationary position $\left(44^{\circ} 40.822^{\prime} \mathrm{N} 1^{\circ} 06.007^{\prime} \mathrm{W}\right)$ by means of a small crane (see Figure 1d). The experimental protocol followed for the in situ detection of chloride and nutrients as well as the data treatment is detailed in the Supporting Information. While $\mathrm{NO}_{3}^{-}$and $\mathrm{NO}_{2}^{-}$potentiometric sensors are re-calibrated once the system is incorporated in the titanium cage and during the deployment in order to correct for temporal effects in the potentiometric readouts, chloride detection does not need any in situ re-calibration as mentioned above.

In situ temporal profiles observed for temperature (CTD), pH (CTD), salinity (CTD), chloride and nitrate are presented in Figure 5. Nitrite levels were lower than the limit of detection of the potentiometric sensor, as later confirmed by analysing the samples by colorimetry (see Table S4). All measured parameters were tide-dependent and are therefore related to tidal flushing effects as reflected in the observed cycles. The first local minimum temperature and maximum $\mathrm{pH}$ coincide with the first maximum salinity at high tide conditions, when the seawater from the Atlantic Ocean floods the point of observation in the Arcachon Bay (between 22:30 and 23:00 h, 
To validate the in situ measurements of chloride, collected samples during the entire deployment were analysed ex situ using the desalination cell and IC. Good correlations were found in all cases (Figure S7) with uncertainties lower than $2 \%$ Diff and, additionally, similar standard deviations for chloride concentration (lower than \pm 2.5 ) were found using IC and the desalination unit operating ex situ (see Figure S7c).

Regarding the temporal profile observed for nitrate (Figure 5d), the registered levels were also clearly tide-dependent. Validation of in situ nitrate measurements was performed by analyzing the samples collected during the deployment using both the system operating ex situ and colorimetry (see Supporting Information). No correlations with in situ measurements are shown because sampling times do not perfectly match and a dashed line is drawn instead (Figure 5d) to demonstrate that in the three cases (in situ, ex situ and colorimetry measurements), nitrate levels 
follow the same trend and the obtained values are comparable. Note that the minimum nitrate levels detected by the developed nitrate sensor $(<2 \mu \mathrm{M})$ are close to the limit of detection and there is an implicit error in the calculation of these concentrations as a consequence of the deviation of the electrode response from linearity, which may be further corrected for better accuracy. ${ }^{43}$

Maximum concentrations occurred at low tide as a consequence of the higher nitrate loading in effluents and underground freshwater discharges in the bay. Thus, the bell shape of this temporal profile is due to the "tidal flushing" effect in the lagoon. The observed concentrations at low tide (5-9 $\mu \mathrm{M})$ are in accordance with those reported by Deborde et al. (5-10 $\mu \mathrm{M})$ during low tide of a tidal creek (one day/night cycle) in spring and summer in samples from the Arcachon Bay. ${ }^{44}$ In this regards, inputs of inorganic nitrogen in the Arcachon Bay has been studied over the years using ex situ analysis after sampling ${ }^{45-47}$ and nutrient export to the Atlantic coastal zone has been modelled. ${ }^{48}$ Nutrients variability linked to freshwater inputs and its relation with phytoplankton primary production has been also studied for the same purpose. ${ }^{49}$

Regional monitoring program (SOMLIT, Service d'Observation en Milieu Littoral) provides nitrate, nitrite, other nutrients levels and major physical parameters measured monthly and the information is published on-line. ${ }^{50}$ However, to the best of our knowledge, the results collected in the present paper constitute the first in situ study of nitrate levels in the Arcachon Bay during a deployment in which salinity-chloride is additionally measured in exactly the same water. In addition, the developed submersible probe may therefore serve as a tool to study the role of the Atlantic Ocean as a (partial) sink of nutrient effluents from the lagoon as well as to follow eutrophication gradients in the water column through in situ data in real time. It could also serve as an alert system for increasing nutrient concentrations and, more generally, to better understand and model nitrate/nitrite biogeochemical cycles in order to detect and prevent any shift in their levels. This type of system would be of major usefulness in coastal systems influenced by human activity inputs such as agriculture regarding quality status requirements.

\section{CONCLUSIONS}

We have developed submersible potentiometric sensors to detect nitrate and nitrite in seawater after inline pretreatment to achieve an electrochemical desalination and passive acidification. The suppression of key interfering ions present in seawater, chloride and hydroxide, makes it 
possible to reach improved limits of detection and to allow for in situ detection of these macronutrients in seawater. In addition, the desalination cell interrogated with cyclic voltammetry provides a calibration-free sensor for chloride detection in environmental water ranging from freshwater to seawater, constituting an alternative to the restricted use of a conductometric sensor in waters of lower salinity. On the other hand, both the desalination and acidification modules may be coupled to other analytical techniques that need any pretreatment for in situ detection of other ions. Moreover, slight modifications of the designed prototypes may allow for the decrease of any redox active ions deposited as silver salt on the working electrode (i.e. other halides) and the depletion/release of any interfering/needed ion in the sample in order to improve the sensing sensitivity.

The submersible device developed here is capable of autonomous operation during deployment, with routines for repetitive measurements, data storage and management, and computer visualization of the data in real time. Currently, a full cycle lasts $1 \mathrm{~h}$ and $40 \mathrm{~min}$ for the sequence: chloride detection, desalination, acidification, nitrate and nitrite potentiometric detection and regeneration of the desalination unit (20 min less without chloride detection). With the current design, the desalination unit needs to be replaced by a new unit for long-term measurements involving more than 30 desalination cycles. Future developments will therefore mainly benefit from a more robust desalinator design.

The environmental application of the proposed sensors was accomplished first in the laboratory using water samples from different regions, Costa Calida (Spain), Plentzia (Spain), Genoa Harbor (Italy) and the Gironde Estuary (France), and then during a $23 \mathrm{~h}$ deployment in the Arcachon Bay (France) by means of the implementation of the sensors in an autonomous submersible device developed in collaboration with the company Idronaut (Italy). The following outcomes were obtained from the observed in situ temporal profiles: (i) Nitrate and chloride levels were tide-dependent and maximum nitrate levels were found at low tide, when there are larger freshwater effluents with higher nutrient loading in the lagoon. (ii) The observed cycles in salinity coincide with chloride levels. A linear correlation between chloride and salinity may be useful to predict chloride from salinity measurements and vice versa. (iii) Nitrites levels were lower than the limit of detection of the potentiometric sensor $(<0.6 \mu \mathrm{M})$. Equilibrium disturbances in nitrate or nitrite levels in coastal areas with high productivity such as the Arcachon Bay, could have major socio-economic effects. This fact strengthens the need for 
reliable, efficient tools such as the newly- developed submersible probe, providing complementary data to existing monitoring programs on biogeochemical cycles of nutrients in coastal areas.

\begin{abstract}
AKNOWLEDGEMENTS
The authors thank the Swiss National Science Foundation, the European Union (FP7-GA 614002-SCHeMA project) for the financial support of this research. M.C. thanks Wallenberg Foundation (WPCRN, K-2017-0804). We are also grateful to the crew of the R/V Planula IV and T. Gil-Diaz for their assistance and pleasant company during the field campaign in Arcachon; M. Castellano and C. Mirasole for the field assistance in other field campaigns developed in Italy as part of the SCHeMA project; T. Gantner for the draw of the desalination cell and the Idronaut team. F. M. specially thanks to P. Povero.
\end{abstract}

\title{
ASSOCIATED CONTENT
}

Supporting Information. Materials and reagents. Validation protocols. Electrode preparation. Experimental protocols for laboratory and in situ measurements. Analytical performance of the sensors (Tables S1 and S2). Information about samples collected from Gironde Estuary (Table S3). Nitrite detection in Arcachon Bay (Table S4). Design and optimization of the desalination cell and chloride detection (Figures S1-S6). Validation of in situ measurements (Figure S7). This material is available free of charge via the Internet at http://pubs.acs.org.

\section{AUTHOR INFORMATION, CORRESPONDING AUTHOR}

mariacb@kth.se; eric.bakker@unige.ch

\section{REFERENCES}

(1) Orr, J. C.; Fabry, V. J.; Aumont, O.; Bopp, L.; Doney, S. C.; Feely, R. A.; Gnanadesikan, A.; Gruber, N.; Ishida, A.; Joos, F.; Key, R. M.; Lindsay, K.; Maier-Reimer, E.; Matear, R.; Monfray, P.; Mouchet, A.; Najjar, R. G.; Plattner, G. K.; Rodgers, K. B.; Sabine, C. L.; Sarmiento, J. L.; Schlitzer, R.; Slater, R. D.; Totterdell, I. J.; Weirig, M. F.; Yamanaka, Y.; Yool, A. Nature 2005, 437, 681-686.

(2) Halpern, B. S.; Walbridge, S.; Selkoe, K. A.; Kappel, C. V.; Micheli, F.; D'Agrosa, C.; Bruno, J. F.; Casey, K. S.; Ebert, C.; Fox, H. E.; Fujita, R.; Heinemann, D.; Lenihan, H. S.; Madin, E. M. P.; Perry, M. T.; Selig, E. R.; Spalding, M.; Steneck, R.; Watson, R. Science 2008, 319, 948-952. 
(3) Webber, H. H.; Thurman, H. V., Marine Biology. Harper Collins: New York, 1991.

(4) Tilman, D. P. Natl. Acad. Sci. USA 1999, 96, 5995-6000.

(5) Andersen, J. H.; Fossing, H.; Hansen, J. W.; Manscher, O. H.; Murray, C.; Petersen, D. L. J. Ambio. 2014, 43, 906-913.

(6) Smith, V. H.; Tilman, G. D.; Nekola, J. C. Environ. Pollut. 1999, 100, 179-196.

(7) Saliot, A., The Mediterranean Sea. Springer: Berlin, 2005.

(8) Cuartero, M.; Bakker, E. Current Opinion in Electrochemistry 2017, 3, 97-105.

(9) Albaiges, J. Int. J. Environ. An. Ch. 2008, 88, 598-598.

(10) David, A. R. J.; McCormack, T.; Morris, A. W.; Worsfold, P. J. Anal. Chim. Acta 1998, 361, 6372.

(11) Ma, J.; Adornato, L.; Byrne, R. H.; Yuan, D. X. Trac-Trend. Ana.l Chem. 2014, 60, 1-15.

(12) Jannasch, H. W.; Johnson, K. S.; Sakamoto, C. M. Anal. Chem. 1994, 66, 3352-3361.

(13) Beaton, A. D.; Cardwell, C. L.; Thomas, R. S.; Sieben, V. J.; Legiret, F. E.; Waugh, E. M.; Statham, P. J.; Mowlem, M. C.; Morgan, H. Environ. Sci. Technol. 2012, 46, 9548-9556.

(14) Li, Q. P.; Hansell, D. A.; Zhang, J. Z. Limnol. Oceanogr-Meth. 2008, 6, 319-326.

(15) http://www.seabird.com/suna (accessed 1 September, 2017).

(16) Johnson, K. S.; Coletti, L. J.; Jannasch, H. W.; Sakamoto, C. M.; Swift, D. D.; Riser, S. C. J. Atmos. Ocean. Tech. 2013, 30, 1854-1866.

(17) Nielsen, M.; Larsen, L. H.; Jetten, M. S. M.; Revsbech, N. P. Appl. Environ. Microbiol. 2004, 70, $6551-6558$.

(18) Revsbech, N. P.; Glud, R. N. Limnol. Oceanogr. Methods 2009, 7, 761-770.

(19) http://www.unisense.com/NOx (accessed 4 February, 2017).

(20) Crespo, G. A. Electrochim. Acta. 2017, 245, 1023-1034.

(21) Bobacka, J.; Ivaska, A.; Lewenstam, A. Chem. Rev. 2008, 108, 329-351.

(22) Bakker, E.; Pretsch, E. Angew. Chem. Int. Edit. 2007, 46, 5660-5668.

(23) Buck, R. P.; Lindner, E. Pure Appl. Chem. 1994, 66, 2527-2536.

(24) Cuartero, M.; Crespo, G. A.; Bakker, E. Chimia 2015, 69, 203-206.

(25) Crespo, G. A.; Bakker, E. Rsc Adv. 2013, 3, 25461-25474.

(26) Bakker, E. Anal. Chem. 2016, 88, 395-413.

(27) Athavale, R.; Dinkel, C.; Wehrli, B.; Bakker, E.; Crespo, G. A.; Brand, A. Environ. Sci. Tech. Let. 2017, 4, 286-291.

(28) Athavale, R.; Kokorite, I.; Dinkel, C.; Bakker, E.; Wehrli, B.; Crespo, G. A.; Brand, A. Anal. Chem. 2015, 87, 11990-11997.

(29) Cuartero, M.; Pankratova, N.; Cherubini, T.; Crespo, G. A.; Massa, F.; Confalonieri, F.; Bakker, E. Environ. Sci. Tech. Let. 2017, 4, 410-415. 
(30) Cuartero, M.; Crespo, G. A.; Bakker, E. Anal. Chem. 2015, 87, 8084-8089.

(31) Pankratova, N.; Cuartero, M.; Crespo, G. A.; Bakker, E. Anal. Chem. 2017, 89, 571-575.

(32) Yuan, D. J.; Anthis, A. H. C.; Afshar, M. G.; Pankratova, N.; Cuartero, M.; Crespo, G. A.; Bakker, E. Anal. Chem. 2015, 87, 8640-8645.

(33) Tercier-Waeber, M. L.; Buffle, J.; Graziottin, F. Electroanal. 1998, 10, 355-363.

(34) Grygolowicz-Pawlak, E.; Sohail, M.; Pawlak, M.; Neel, B.; Shvarev, A.; de Marco, R.; Bakker, E. Anal. Chem. 2012, 84, 6158-6165.

(35) Pankratova, N.; Afshar, M. G.; Yuan, D. J.; Crespo, G. A.; Bakker, E. Acs Sensors. 2016, 1, 48-54.

(36) Cuartero, M.; Crespo, G. A.; Afshar, M. G.; Bakker, E. Anal. Chem. 2014, 86, 11387-11395.

(37) Millero, F. J. Limnol. Oceanogr. 1984, 29, 1317-1321.

(38) Cox, R. A.; Culkin, F.; Riley, J. P. Deep-sea research 1967, 14, 203-220.

(39) Qian, Y.; Zhao, Y.; Wu, Q. L.; Yang, Y. Sens. Act. B 2018, 260, 86-105.

(40) Muller, B. J.; Rappitsch, T.; Staudinger, C.; Ruschitz, C.; Borisov, S. M.; Klimant, I. Anal. Chem. 2017, 89, 7195-7202.

(41) Woody, C.; Shih, E.; Miller, J.; Royer, T.; Atkinson, L. P.; Moody, R. S. Mar. Technol. Soc. J. 2000, 34, 26-33.

(42) Manaud, F.; Bouchet, J-M.; Deltreil, J-P.; Maurer, D.; Trut, G.; Auby, I.; Dreno, J-P.; Masson, N.; Pellier, C.; L’Yavan,c J., Etude Integree Du Bassin d'arcachon. Tome II. Ifremer, 331pp, 1997.

(43) Barbooti, M., Environmental applications of instrumental chemical analysis, CRC Press, Boca Raton, 2015.

(44) Deborde, J.; Anschutz, P.; Auby, I.; Gle, C.; Commarieu, M. V.; Maurer, D.; Lecroart, P.; Abril, G. Mar. Chem. 2008, 109, 98-114.

(45) Castel, J.; Caumette, P.; Herbert, R. Hydrobiologia 1996, 329, R9-R28.

(46) Rimmelin, P.; Dumon, J. C.; Maneux, E.; Goncalves, A. Estuar. Coast. Shelf. S. 1998, 47, 649659.

(47) Rysgaard, S.; RisgaardPetersen, N.; Sloth, N. P. Hydrobiologia 1996, 329, 133-141.

(48) Canton, M.; Anschutz, P.; Coynel, A.; Polsenaere, P.; Auby, I.; Poirier, D. Biogeochemistry 2012, 107, 361-377.

(49) Gle, C.; Del Amo, Y.; Sautour, B.; Laborde, P.; Chardy, P. Estuar. Coast. Shelf. S. 2008, 76, 642656.

(50) http://somlit.epoc.u-bordeaux1.fr/fr/ (accessed 15 November, 2017).

(51) http://www.tutiempo.net/arcachon.html?datos=calendario - cal (accessed 1 June, 2017).

(52) http://www.maree.info/136?d=20170515 (accessed 1 June, 2017).

(53) http://www.maree.info/136?d=20170516 (accessed 1 June 2017). 


\section{Figures Captions}

Figure 1. (a) Scheme of the developed fluidics for in situ measurements (NO=Normally Open, $\mathrm{NC}=$ Normally Close, $\mathrm{CAL} \mathrm{SOL}=$ Calibration solution, $\mathrm{RE}=$ Reference Electrode). (b) Image of the submersible probe based on the valve (1), the desalination module (2), the acidification module (3) and the potentiometric flow cell (4). The system is placed inside the water- and pressure-proof cylindrical housing (5) made of acetylic copolymer (Deldrin). ${ }^{33}$ (c) The probe is incorporated into the titanium cage together with the pump and the CTD multiparemeter probe (6: filter for seawater, 7: pump, 8: unit containing the electrochemical sensors, 9: bag containing the calibration solution, 10: bag containing the $\mathrm{HCl}$ solution, 11: CTD). (d) The submersible device was deployed in the Arcachon Bay from a boat using a small onboard crane.

Figure 2. Calibration graphs obtained for (a) nitrate and (b) nitrite using the developed flow potentiometric cell based on miniaturized all-solid-state electrodes.

Figure 3. Cyclic voltammograms observed at increasing chloride concentrations in (a) synthetic $\mathrm{NaCl}$ solutions and (b) freshwater/seawater mixtures. Reference solution = water sample that is measured. (c) Correlation between chloride concentrations measured using ion chromatography and the desalination cell in samples collected in the Gironde Estuary (France).

Figure 4. Plots of chloride versus salinity measured in (a) samples collected in the Gironde Estuary and (b) the $23 \mathrm{~h}$ deployment in the Arcachon Bay. Blue squares indicate predicted salinity values from the observed chloride-salinity linear relationship. Dashed line indicates the extrapolation of the chloride-salinity linear relationship to lower chloride values.

Figure 5. In situ temporal profiles obtained for (a) temperature (CTD), (b) pH (CTD), (c) salinity and chloride and (d) nitrate during the deployment of $23 \mathrm{~h}$ (starting from May 15, 2017 at 16:00 to May 16, 2017 at 15:00) in the Arcachon Bay $\left(44^{\circ} 40.822^{\prime} \mathrm{N} 1^{\circ} 06.007^{\prime} \mathrm{W}\right)$. The deployment depth was $2.3 \pm 0.3 \mathrm{~m}$. The dissolved $\mathrm{O}_{2}$ concentration was $7.5 \pm 0.3 \mathrm{ppm}$, corresponding to $101.2 \pm 3.2 \%$ for oxygen saturation within the monitoring window. Light hours are shaded in gray. ${ }^{51}$ The local times for high and low tides (HT and LT, respectively) were determined according to the tidal record at Jetée d'Eyrac $\left(44^{\circ} 40^{\prime} \mathrm{N} 1^{\circ} 10^{\prime} \mathrm{W}\right)$ and considering the temporal evolution of the seawater level in the Arcachon Bay. ${ }^{52,53}$ 


\section{Tables}

Table 1. Nitrate and nitrite analysis in several samples $(n=3)$ from different locations: Costa Calida (Murcia, Spain), Plentzia Bay (Bilbao, Spain) and Genoa Harbor (Italy).

\begin{tabular}{cc|c|c|cc|cc|cc}
\hline & & \multicolumn{2}{|c|}{ chloride $(\mathrm{mM})$} & \multicolumn{2}{c|}{$\mathrm{pH}$} & \multicolumn{2}{c}{$\mathrm{NO}_{3}{ }^{-}$} & \multicolumn{2}{c}{$\mathrm{NO}_{2}{ }^{-}(\mu \mathrm{M})$} \\
\hline sample & salinity & $\mathrm{CV}$ & $\mathrm{IC}$ & before $^{\mathrm{a}}$ & after & potentiometry & colorimetry & potentiometry & colorimetry \\
\hline 1 & 35.2 & 586.9 & 583.1 & 8.11 & 4.82 & $12.3 \pm 1.6$ & $13.1 \pm 2.0$ & $1.15 \pm 0.09$ & $1.23 \pm 0.10$ \\
2 & 32.2 & 527.0 & 532.3 & 7.98 & 4.91 & $5.7 \pm 0.7$ & $5.5 \pm 1.0$ & $0.71 \pm 0.07$ & $0.68 \pm 0.10$ \\
3 & 34.3 & 569.2 & 575.2 & 8.15 & 4.87 & $2.1 \pm 0.3$ & $2.3 \pm 0.7$ & $<0.5$ & $0.11 \pm 0.10$ \\
\hline
\end{tabular}




\section{For TOC only}

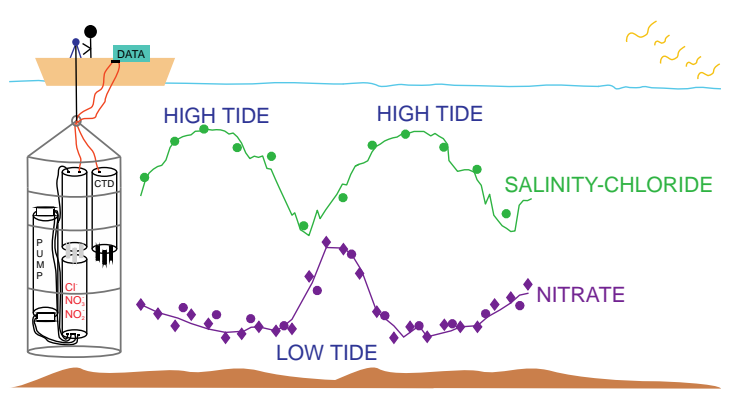


Figure 1

a)

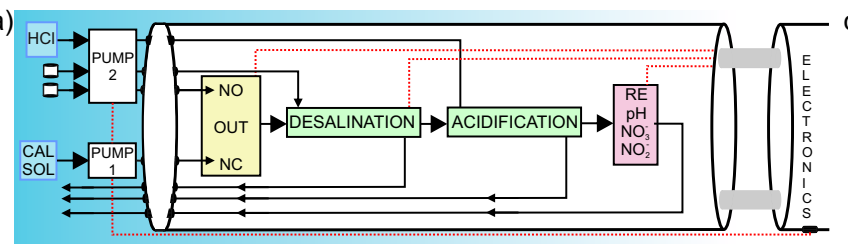

b)
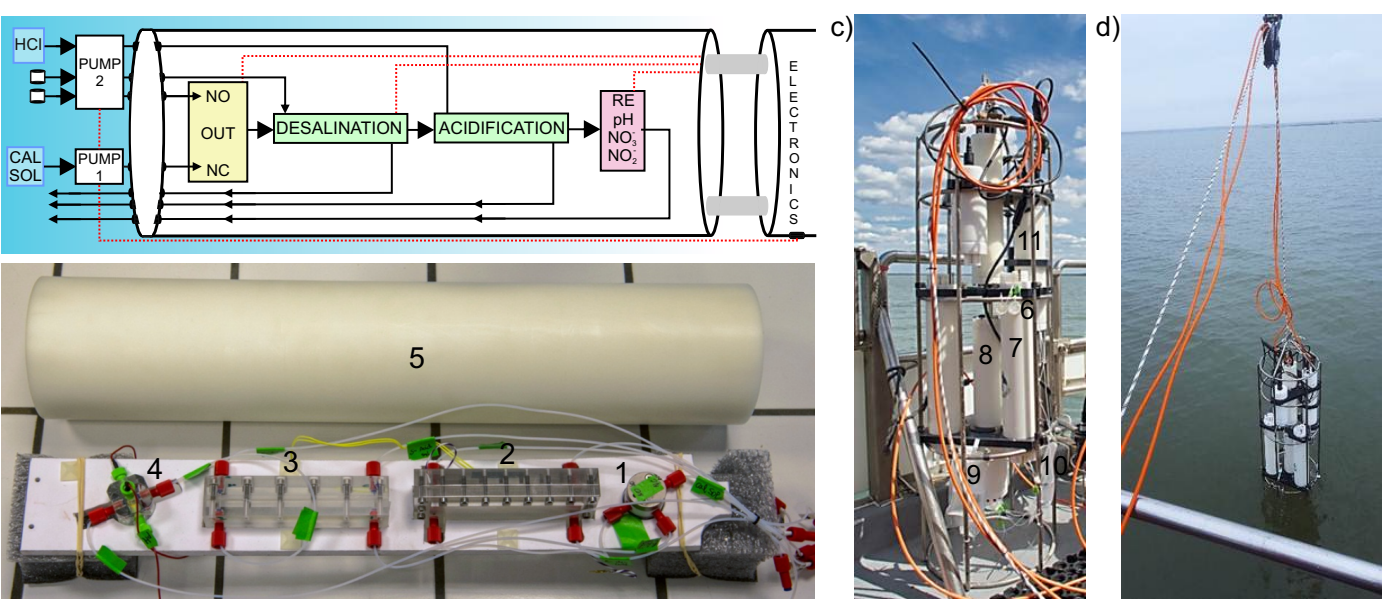
Figure 2
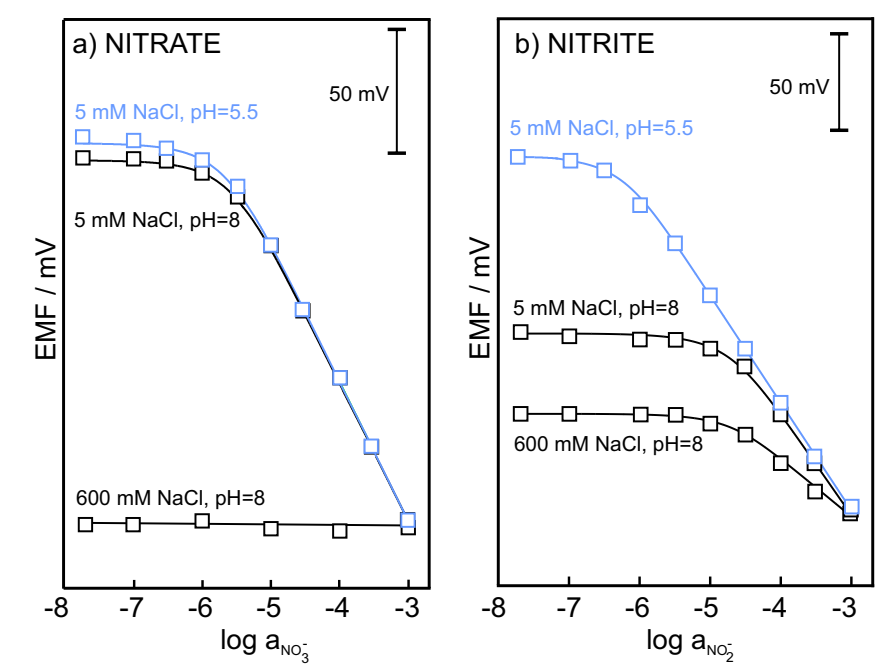

23

24

25

26

27

28

29

30

31

32

33

34

35

36

37

38

39

40

41

42

43

44

45

46

47

48

49

50

5

53

54

55

56

57

58

59

60

ACS Paragon Plus Environment 
Figure 3
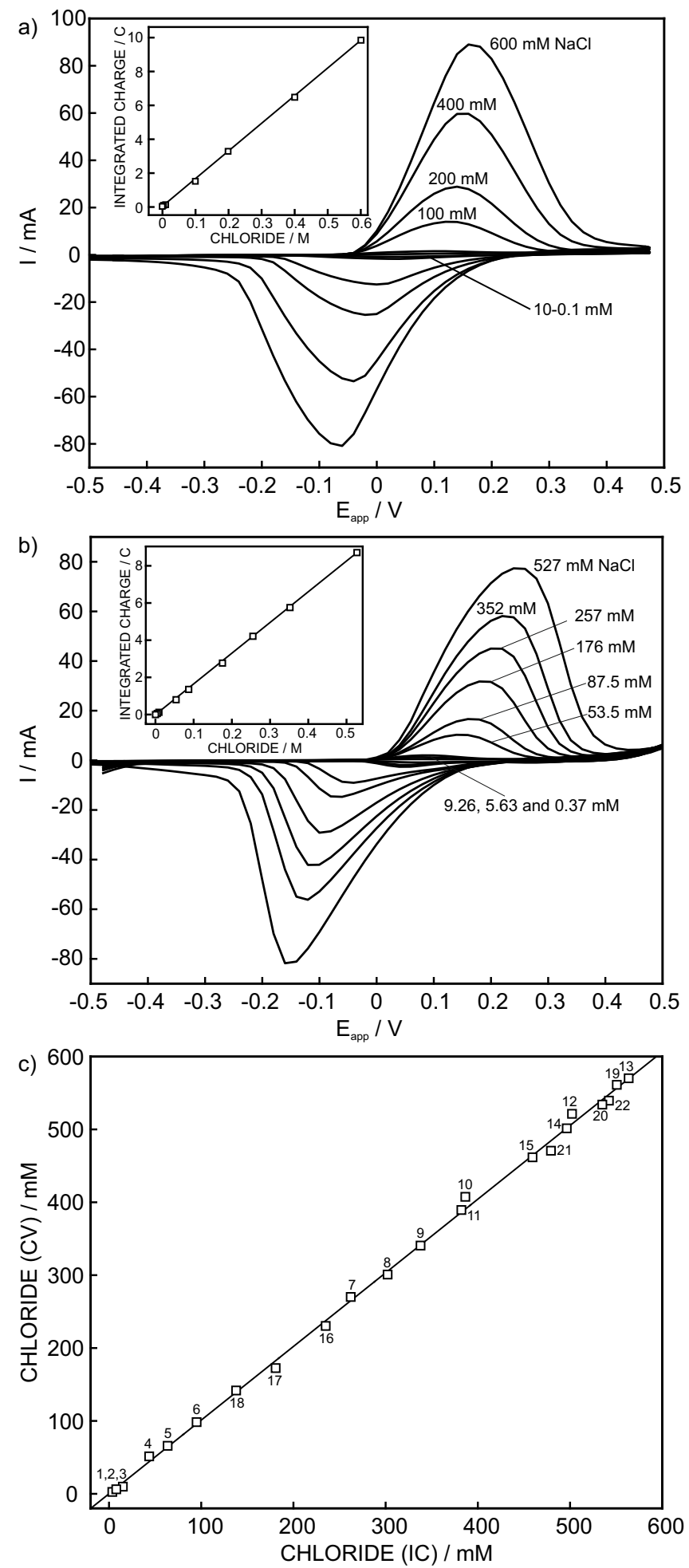

ACS Paragon Plus Environment 


\section{Figure 4}
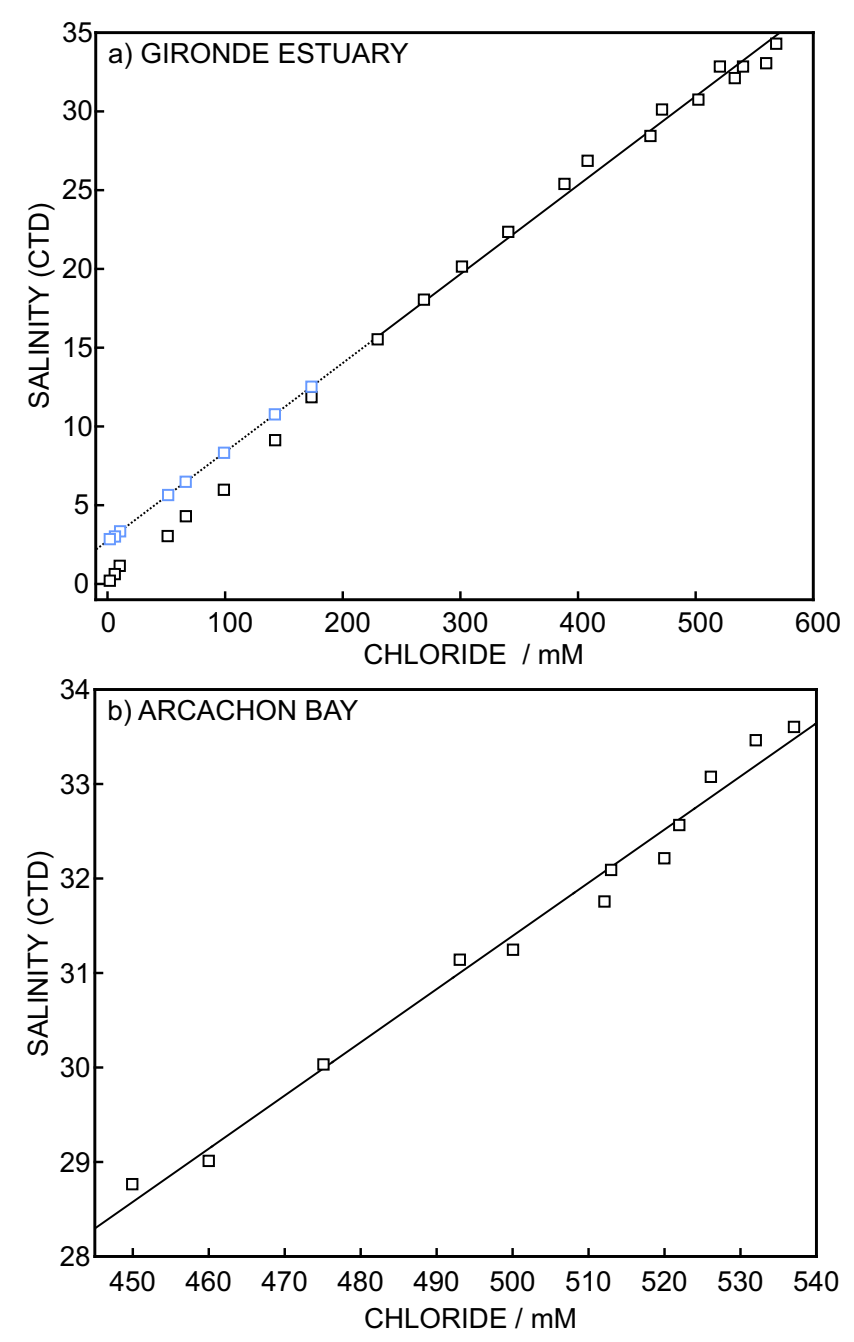

ACS Paragon Plus Environment 
Figure 5
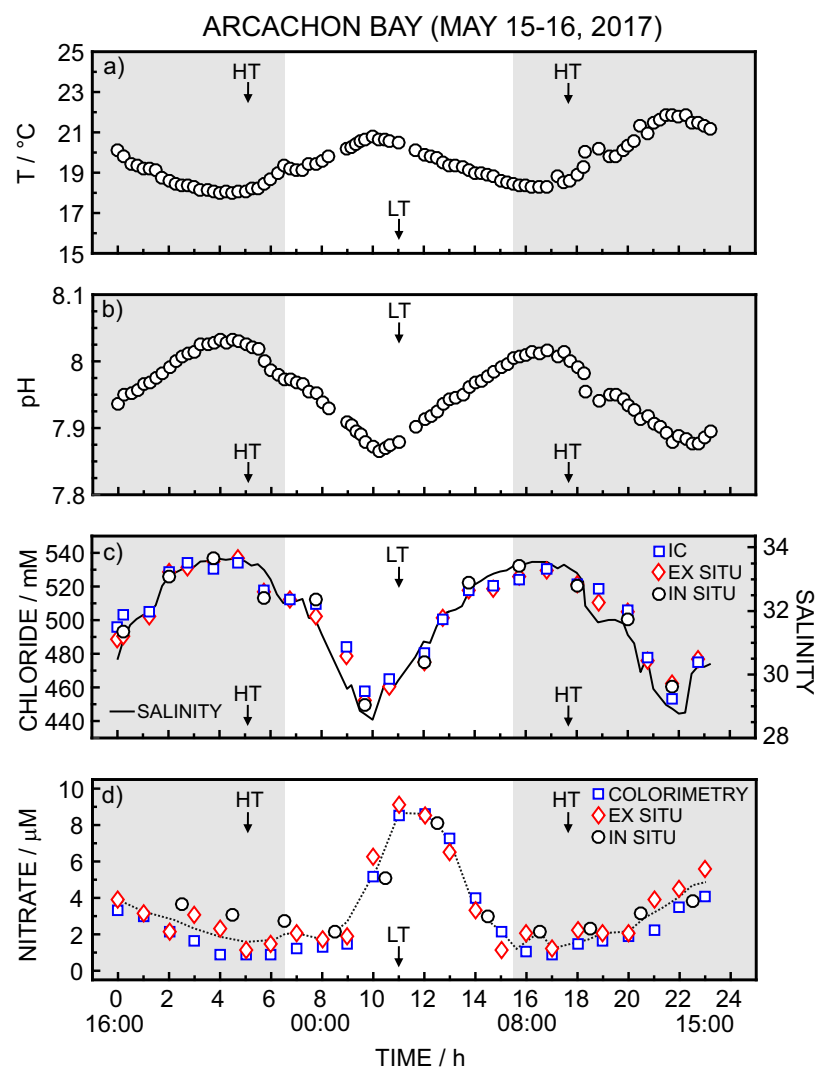